\title{
Modeling of quantum nanomechanics
}

\section{Jauho, Antti-Pekka; Novotny, Tomas; Donarini, Andrea; Flindt, Christian}

Published in:

10th International Workshop on Computational Electronics, 2004. IWCE-10 2004. Abstracts.

Link to article, DOI:

10.1109/IWCE.2004.1407327

Publication date:

2004

Document Version

Publisher's PDF, also known as Version of record

Link back to DTU Orbit

Citation (APA):

Jauho, A-P., Novotny, T., Donarini, A., \& Flindt, C. (2004). Modeling of quantum nanomechanics. In 10th International Workshop on Computational Electronics, 2004. IWCE-10 2004. Abstracts. IEEE.

https://doi.org/10.1109/IWCE.2004.1407327

\section{General rights}

Copyright and moral rights for the publications made accessible in the public portal are retained by the authors and/or other copyright owners and it is a condition of accessing publications that users recognise and abide by the legal requirements associated with these rights.

- Users may download and print one copy of any publication from the public portal for the purpose of private study or research.

- You may not further distribute the material or use it for any profit-making activity or commercial gain

- You may freely distribute the URL identifying the publication in the public portal

If you believe that this document breaches copyright please contact us providing details, and we will remove access to the work immediately and investigate your claim. 


\author{
Modeling of Quantum Nanomechanics \\ Antti-Pekka Jauho, Tomáš Novotný, Andrea Donarini and Christian Flindt \\ MIC - Department of Micro and Nanotechnology, Technical University of Denmark, \\ Ørsteds Plads, Bldg. 345E, DK-2800 Lyngby, Denmark \\ E-mail: antti@mic.dtu.dk
}

Microelectromechanical systems (MEMS) are approaching the nanoscale, which ultimately implies that the mechanical motion needs to be treated quantum mechanically. An example is the experiment by Park et al. [1], where a C60-molecule is placed between a metallic substrate and an STM-tip. The measured IV-curves display features that can be related to the mechanical vibrations of the molecule. Already earlier it was suggested theoretically [2] that a nanoscopic movable metallic grain, when operated in the Coulomb blockade regime, can move charges oneby-one between source and drain contacts. This orderly transport was coined the shuttle regime. In recent years our group has developed theoretical methods to analyze the shuttle transition in the quantum regime [3], focusing not only in the IV-curve, but also considering noise, which is an important diagnostic tool in unraveling the microscopic transport mechanisms.

Our theoretical analysis is based on a numerical solution of a generalized master equation (GME) for the density matrix. This equation is obtained by tracing the Liouville equation over the bath degrees of freedom (i.e., the free fermions of the electronic contacts, and the damping of the mechanical degree of freedom due to a bosonic environment). The GME is still an operator equation for the electronic degrees of the movable nanoscopic object, as well as the quantized motion. It can be cast in a matrix form by using the eigenmodes of the quantized motion as a basis. For physical values of the parameters the resulting matrix equations are large and nonsparse, characteristically of the size $10^{4} \times 10^{4}$, and advanced numerical methods are necessary. We have used the Arnoldi iteration scheme to reformulate the large matrix problem in terms of a smaller system in an appropriate Krylov subspace. Typically, matrices of modest dimensions are needed, and no supercomputing is necessary. An appropriate preconditioning, however, was absolutely crucial for convergence. The calculation for the steady state current involves a homogeneous equation, while the noise calculation requires the solution of an inhomogeneous equation (where the result of the current calculation is used as an input), however the solution can be achieved conveniently with the generalized minimum residual method, available in MATLAB. The final results can be interpreted physically with the help of the Wigner functions (an example is shown in the attached figure), which allows one to distinguish between different transport mechanisms. Our main physical conclusions are: (i) For certain parameters, the system may exhibit two different transport channels (sequential tunneling vs. shuttling), (ii) Shuttling is a low noise phenomenon, and (iii) As the shuttling transition is approached, giant enhancements of the noise may be present.

\title{
References:
}

[1] H. Park, J. Park, A. K. L. Lim, E. H. Anderson, A. P. Alivisatos, and P. L. McEuen, Nature 407, $57(2000)$.

[2] L. Y. Gorelik, A. Isacsson, M. V. Voinova, B. Kasemo, R. I. Shekther, and M. Jonson, Phys. Rev. Lett. 80, 4526 (1998).

[3] T. Novotný et al., Phys. Rev. Lett. 90, 256801 (2003); ibid. 92, 248302 (2004) .

A full journal publication of this work will be published in the Journal of Computational Electronics. 


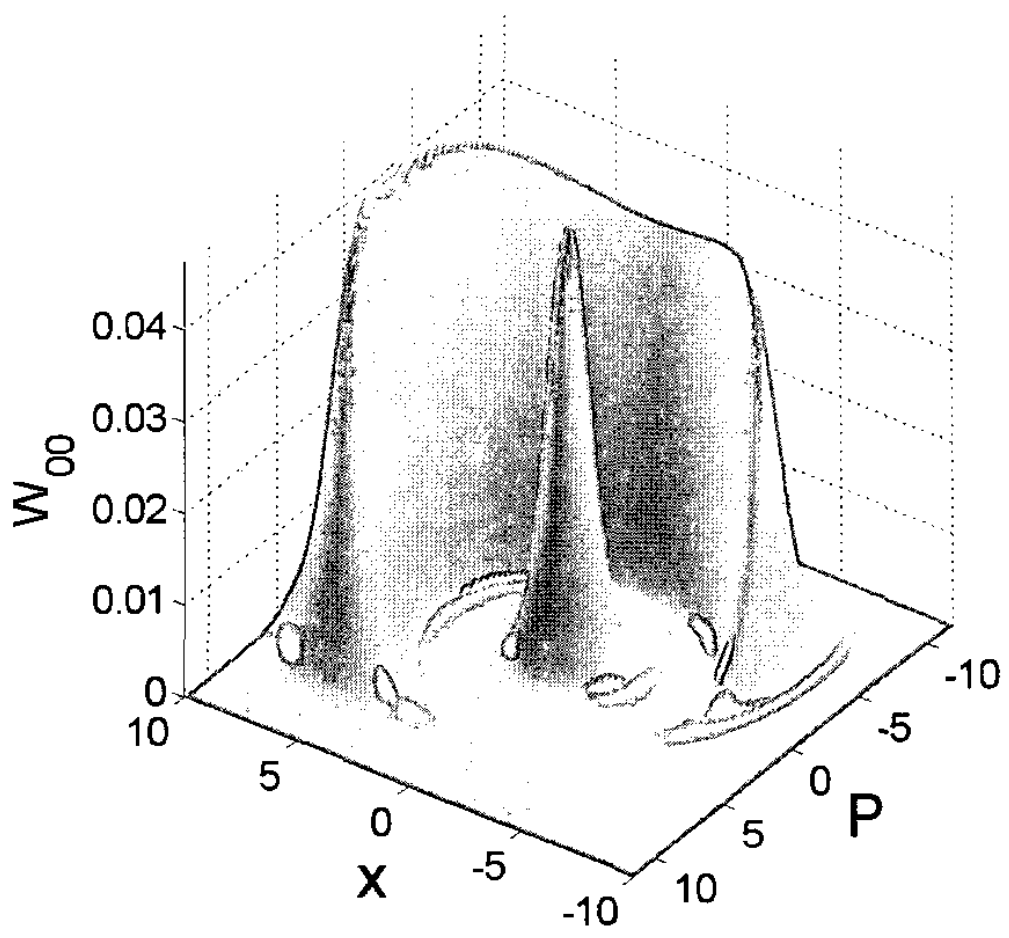

Wigner function $\mathrm{W}_{00}$ for the unoccupied state of the movable quantum dot. For the chosen parameters transport through the dot exhibits two different mechanisms: (i) The symmetric central peak reflects incoherent sequential tunneling, while (ii) The asymmetric ring indicates a highly orderly transport, i.e., shuttling, where the dot is unoccupied when returning from the drain contact, i.e., positive $x$ and negative $p$. The Wigner function for the charged shuttle $W_{11}$ would show a complementary behavior, i.e., large values for negative $x$ and positive $p$.

A full journal publication of this work will be published in the Journal of Computational Electronics. 